\title{
¿Decisión de mujeres? El debate político institucional en torno al aborto durante la posdictadura en Chile (1989-2015)
}

Women's decision? The political institutional debate concerning abortion during the post-dictatorship period in Chile (19892015)

\section{Karen Alfaro-Monsalve*, María JosÉ LeIVA-VARGAS ${ }^{* *}$}

\section{Resumen}

Este artículo propone lineamientos teóricos para analizar el trasfondo del debate político respec-

\footnotetext{
Instituto de Historia y Ciencias Sociales, Isla Teja s/n, Universidad Austral de Chile. Correo electrónico: karen.alfaro@uach.cl

** Instituto de Historia y Ciencias Sociales, Isla Teja s/n, Universidad Austral de Chile. Correo electrónico: maria.jose_leiva@hotmail.com

to al aborto durante la posdictadura en Chile, esto es, a lo largo de los primeros veinte años, luego del fin de la dictadura militar. Los roles de género, lasexualidad de la mujery la interpretación del cuerpo son cuestiones que se profundizan con el fin de comprender la problemática social que afecta a las mujeres de nuestro país, quienes conviven a diario con un sistema construido social e históricamente que las discrimina e invisibiliza como sujetos. Lo anterior se ve reflejado en las opiniones y argumentos emitidos por la clase política en un tema que sólo concierne a ellas y sus cuerpos, pero que se insiste en analizar sin incluirlas en la discusión.

Palabras clave: aborto, género, cuerpo, sexualidad, patriarcado, salud sexual y reproductiva, debate político.

\section{Abstract}

This article proposes theoretical guidelines to analyze the background of the political debate surrounding abortion in the post-dictatorship period in Chile, during the first twenty years after the end of it. Gender roles, woman's sexuality and the interpretation of the body are issues which deepen the understanding of the social problem that affects women in our country, who daily deal with a socially and historically constructed system that discriminates and makes them invisible as subjects. This is reflected in the views and arguments issued by the political class in a topic that concerns only women and their bodies, but which insists on analyzing the topics mentioned without including women in the discussion.

Key words: abortion, gender, body, sexuality, patriarchy, sexual and reproductive health, political debate. 


\section{Introducción}

El presente trabajo se sitúa en la línea de la historia social y política para abordar el debate en torno al aborto desde el fin de la dictadura de Augusto Pinochet. En 1989 se dicta la ley 18.826, en reemplazo de la disposición del Código Sanitario que regía desde la década del 30. En el año 2015 se presentó la propuesta de despenalización del aborto terapéutico, bajo el segundo gobierno de la presidenta Michelle Bachelet. Durante la posdictadura, existe sólo un consenso en la clase política sobre los temas estructurales: respecto al modelo neoliberal y el tipo de democracia semisoberana (Hunneus 2014). Sin embargo, habrá diferencias profundas acerca de las problemáticas en torno a los Derechos Humanos y los llamados "temas valóricos", que determinan los principales debates públicos y de conflicto en tal período.

A lo largo de la dictadura militar, se instaló un proyecto de carácter conservador, propuesto para fortalecer los roles tradicionales de género y de la mujer en particular. Para lograrlo se enalteció la figura de madre/esposa, y se la instaló como eje central en la reproducción del orden y en la formación de ciudadanos "serviciales a su patria". Es bajo este contexto que el artículo 119 del Código Sanitario, que permitía la práctica del aborto, es sustituido por una normativa restringida que deviene en su posterior criminalización.

A partir del año 1990, el debate político sobre el aborto está mediado por aquellos argumentos que dan continuidad al legado conservador y tradicional de la dictadura militar, en relación con los derechos sexuales y reproductivos. Estos debates se enfrentan a una realidad estadística que da cuenta de la existencia de la práctica del aborto, tanto en clínicas clandestinas pagadas, como a partir de diversos mecanismos que ponen en serio riesgo la vida, principalmente de mujeres de los sectores populares. Esto convierte al aborto, entonces, en una problemática vinculada directamente con la gran desigualdad socioeconómica que afecta a nuestro país.

De este modo, buscaremos explicar las razones que llevaron a penalizar el aborto y a retirar de la escena pública la discusión sobre este tema durante la posdictaura, identificando el contexto histórico que permitió legislar al respecto en su momento, y las causas que motivaron la profundización de los derechos sexuales y reproductivos de las mujeres y sus familias durante el siglo XX. Además, revisaremos aquellas razones que lo prohibieron, restringiendo la libertad y autonomía de las mujeres en la sociedad chilena. Para hacer esto, tomaremos en cuenta el debate político que se ha generado en torno al aborto durante la posdictadura entre 1990 y 2015 , y la situación de la mujer frente al Estado, en particular lo que dice relación con la desigualdad civil que afecta a las mujeres en nuestro país y la poca o nula autonomía que ellas ostentan.

En esta línea de trabajo, nos parece esencial planear como hipótesis que la legislación en Chile, entre 1931 y 1973, significó una apertura al aborto terapéutico, debido al carácter epidémico que su realización clandestina implicaba. De ahí las altas cifras de mujeres que ingresaban a los diversos centros de salud a lo largo del país, producto de un aborto mal realizado, y la alta tasa de mortalidad materna como consecuencia del mismo. Esto conllevó a que el aborto dejara de ser una problemática reservada al ámbito privado y se convirtiera en un área de interés del Estado, como parte de una política pública. 
También afirmamos que, durante el período estudiado, el aborto es analizado como un problema valórico y no como un asunto asociado directamente con la salud pública, debido a la gran influencia y poder que adquirió la Iglesia Católica en el ámbito político chileno durante los años 80. Especialmente, nos referimos con esto a la corriente de la jerarquía eclesiástica y a los sectores de la clase política que representan el ultraconservadurismo y la herencia del proyecto dictatorial.

Como hipótesis complementaria, nos parece que el debate político sobre el aborto durante la posdictadura se vio obstaculizado para las mujeres debido a las políticas de consenso del modelo de transición pactada, en las que se incluía la continuidad del proyecto de mujer consolidado en dictadura. Por lo tanto, abrir la discusión a temas como el aborto significaba avanzar hacia una real democratización.

Dicho esto, el presente artículo busca sistematizar la discusión política institucional sobre el aborto en la posdictadura, con el objetivo de distinguir los discursos al interior de la clase política, desvelando los elementos que se hallan en juego desde el poder. Trabajaremos con la metodología de la historia en el tratamiento de fuentes y análisis en función de las principales categorías de investigación. Las fuentes consultadas responden a documentación oficial, documentos especializados y de prensa, como principal dispositivo de difusión del discurso de la clase política.

\section{El género en el análisis histórico}

El género es en todas las sociedades un principio básico de organización social. Se trata del género entendido como sistema simbólico de opuestos-complementarios, en términos bipolares. Así, estudiar a las mujeres implica también estudiar a los hombres y todo el sistema social de una cultura determinada. El sistema de género no es simétrico, sino que es jerárquico. Es el campo donde se articula el poder, según Joan Scott (2008), pues los contenidos de género varían entre las culturas, aunque el predominio de lo masculino sea una constante transcultural.

La importancia de los estudios de género para esta investigación es fundamental debido a que nos permite repensar el género como una categoría para el análisis histórico, con la finalidad de explicar las relaciones sociales construidas desde las diferencias de género. Esta categoría emerge, por lo tanto, como una alternativa para estudiar las desigualdades sociales establecidas, como una extensión de la diferenciación sexual, que resulta ser una construcción histórica y social de lo femenino y lo masculino. Nuria Varela lo plantea así:

La noción de género surge a partir de la idea de que lo "femenino" y lo "masculino" no son hechos naturales o biológicos, sino construcciones culturales. (...) normas, obligaciones, comportamientos, pensamientos, capacidades y hasta carácter que se han exigido que tuvieran las mujeres por ser biológicamente mujeres (2005: 181).

Es factible por ello afirmar que el género es una construcción social que atribuye a los sexos, hombre y mujer, cualidades y comportamientos intrínsecos que establecen su función en la sociedad, de acuerdo a sus características sexuales biológicas primarias $y$ que, en consecuencia, determina las relaciones sociales entre ambos, a través de los procesos de socialización de los que los 
sujetos forman parte desde su infancia. De esta manera, el género "masculino" queda atribuido exclusivamente al sexo "hombre" y, por exclusión, el género "femenino" se adjudica al sexo "mujer", cumpliendo cada uno un rol diferente en la sociedad. Por lo tanto, el género corresponde a una creación social de ideas sobre los roles adecuados para mujeres y hombres como cuerpos sexuados.

De acuerdo con lo anterior, la función social de las mujeres en la sociedad se ha visto reducida, por su naturaleza biológica, a la maternidad y la crianza de los hijos, marginando tradicionalmente su campo de acción al ámbito privado y reservando la esfera pública a lo masculino. Esto reproduce un orden de género en la política, entendiendo que el sistema sexo/género determina también los valores y significados que rigen la conducta de los hombres (De Lauretis 1989).

El mundo industrial contemporáneo se constituye en una "fábrica de género". El desarrollo de la burguesía y los patrones culturales que esta clase construye, necesitan de la mujer como guardiana de la mantención de un orden que les permita asegurar los privilegios burgueses, desarrollando una serie de arquetipos de lo femenino. La femineidad se representa atrapada de las emociones maternales, se le delega a la mujer el cuidado del otro, en función de los hijos y del esposo, construcción cultural de un modelo de domesticidad.

Al naturalizarse este modelo de relaciones de género, acciones y discursos críticos-feministas pasan al plano de lo antinatural y no normal. Se produce una fuerte tensión entre la modernidad centrada en el individuo y la imagen de la mujer, que no tiene esa individualidad, porque se construye en función del otro, hijos, esposos, etc. Adicionalmente, la mujer es invisibilizada en la escala de la producción, su trabajo se constituye en un agregado al masculino, en suplementario, además, no se reconoce culturalmente la labor femenina en el duro trabajo doméstico. Es en este contexto donde la articulación de un discurso feminista que apunta a concientizar frente a los dispositivos de domesticidad tiene lugar, logrando romper el silencio y verbalizar la opresión.

Si bien el movimiento feminista ha jugado un rol clave en la historia que transita desde el movimiento sufragista, hasta sus luchas desde el pacifismo, contra el racismo, por los derechos sexuales, reproductivos y sociales, se ha visto en varios momentos históricos limitado por la cooptación de las orgánicas políticas partidistas, que logran neutralizar su discurso. El feminismo se aboca a la toma de conciencia de las mujeres de su propia condición de subordinación en una sociedad dirigida y planteada por hombres, por lo que busca transformaciones en la estructura social, con el objetivo de ser reivindicadas y que se las reconozca como sujetos históricos.

De esta manera, la lucha se ha centrado en romper la dicotomía entre el espacio interior doméstico y el privado, para así ser reconocidas en el espacio abierto social y público. Este trabajo tiene la intención de ayudar a transformar los sectores políticos, en especial el de las mujeres, respecto de su condicionamiento tanto natural como social, que se ha visto determinado por la maternidad y crianza de los hijos. Tradicionalmente, se pensaba que su participación política en la sociedad pondría en riesgo a la familia, por el 
consecuente descuido de su labor de madre y esposa. Julieta Kirkwood señala que

las ideologías de izquierda, centro o derecha, instituyen a la mujer en el ámbito privado doméstico; sin relevarse, hacer cuestión, ni de la "inexpresividad" de los partidos más progresistas en cuanto a la condición de la mujer, ni de la notable "expresividad" de las ideologías de derecha para hacer caudal de la orfandad política femenina (1983: 2).

En Chile, el movimiento feminista adquiere una relevancia crucial en el siglo XX a partir de la presencia del Movimiento Pro Emancipación de la Mujer Chilena (MEMCH), que si bien fue reconocido por su rol en la lucha por la obtención del derecho al sufragio de la mujer, también abogaba por la lucha contra la desigualdad socioeconómica que afectaba a las mujeres de las clases populares. Además, este movimiento demandó soluciones al Estado frente a las altas tasas de mortalidad infantil y materna, y de los altos índices de aborto, y buscó la mejora de la situación de las mujeres en el país, revindicando derechos políticos/jurídicos, como también sociales y económicos.

Sin embargo, y a pesar de la consolidación del movimiento feminista dentro de la realidad nacional como uno de los actores políticos que profundiza la lucha por alcanzar la igualdad de género, ésta experimentaría un determinante retroceso con la irrupción de la dictadura militar desde 1973. La fuerte represión ejercida como política de Estado tenía como objetivo, junto con fortalecer el rol conservador de la mujer en la sociedad, entregarle un rol protagónico en los cambios productivos del país, en el marco de la expansión del neoliberalismo, siendo la mano de obra femenina la que ingresa al mercado laboral mayoritariamente en condiciones de precariedad y flexibilidad.
En relación con lo señalado, podemos afirmar que la mujer recibe bajo la dictadura una doble función: la reproducción del orden autoritario en su rol de madre/esposa, por una parte, y, por otra, en la producción, como actor central en la actividad de servicios motores del modelo neoliberal. Por lo señalado, el cuerpo femenino se constituye en el espacio de poder político y económico.

Dicho esto, podemos sostener que el cuerpo de la mujer es comprendido, fundamentalmente, como un medio para la reproducción -la maternidad-, y no como sujeto social y político. En una sociedad patriarcal, la fertilidad de la mujer aparece como característica fundamental, "un bien" que determina la valoración que se tiene o no de ella en función de esta cualidad. Por ello la reproducción se constituye, a la larga, en el acto de "realización" del sujeto en cuanto mujer según el canon social establecido; la "madre/esposa" y "ángel del hogar" se instalan como los arquetipos reproducidos por la cultura.

Las mujeres no controlan la reproducción con autonomía, aún cuando los embarazos y el período de lactancia son de competencia de sus cuerpos. La mujer no dispone de su propio cuerpo, ya que es construido por socialización para ser apreciado estética, valórica y sexualmente a partir de parámetros masculinos que se reflejan también en el Estado. Así, su cuerpo es convertido en un cuerpo-paraotros, un objeto percibido y valorado por la subjetividad de un otro, un tercero.

Las mujeres, al no tener políticamente el control de sus cuerpos, no pueden, entonces, "negarse a ser madres", y a pesar de los avances científicos en materia de anticoncepción, 
interrumpir un embarazo no deseado transgrediría el supuesto "orden natural". El embarazo inmediatamente anula la voluntad de la mujer, pues su única función a partir de ese instante es dedicarse a ser madre y a la crianza de los hijos, renunciando en innumerables oportunidades a proyectos de vida personales. De este modo, el cuerpo de la mujer aparece como un medio de procreación; no es un sujeto, es una matriz, pero sin la mujer.

Catharine Mackinnon (1995) explica que el contexto social de la desigualdad de género es lo que niega a la mujer el control de su cuerpo en relación con la reproducción, y pone ese control en manos de los hombres. Se ha arrebatado a las mujeres todo el control que pudieran tener sobre ellas mismas, mediante mecanismos de la estructura económica y política, tales como el acceso a métodos anticonceptivos, la educación sexual, el aprendizaje adquirido de la sociedad, la presión que las reprime, la pobreza, la dependencia económica forzada, la violencia de género y la poca efectividad de la aplicación de las leyes contra la violencia sexual, lo cual se traduce en que, finalmente, las mujeres no controlen estos factores $\mathrm{y}$, por lo tanto, tampoco las condiciones en las que se produce el embarazo.

El aborto, en estas circunstancias, emerge como un derecho que debiera estar garantizado para que así las mujeres retomen parte del control de sus cuerpos y, por ende, de sus vidas. De lo contrario, estamos consagrando la decisión en un tercero.

La sociedad en la que vivimos permite la construcción de estos significados y constructos sociales que rigen nuestras vidas en comunidad. El patriarcado es un sistema que establece y legitima la autoridad de los hombres por sobre las mujeres, siendo ellas subordinadas como seres inferiores a los primeros. Nuria Varela definió el patriarcado de una manera clara y precisa, afirmando que éste es:

[u]na forma de organización política, económica, religiosa y social basada en la idea de autoridad y liderazgo del varón, en la que se da el predominio de los hombres sobre las mujeres; del marido sobre la esposa; del padre sobre la madre, los hijos y las hijas; de los viejos sobre los jóvenes y de la línea de descendencia paterna sobre la materna (2005: 177).

Es posible comprender la profundidad del entramado de relaciones de poder que abarca el patriarcado, un sistema que atraviesa toda la sociedad de manera transversal. Esto es así pues el predominio del hombre se encuentra en cada aspecto de la vida pública y, también, en el ámbito privado, controlando con una fuerte presencia el espacio en el que se desenvuelve la mujer.

Gerda Lerner (1990) es enfática al explicar que el patriarcado corresponde a una construcción social e histórica y que, por lo tanto, no responde a un orden natural determinado, por lo que está sujeto a transformaciones y cambios profundos. La inferioridad de la mujer está basada, entonces, en la condición biológica que le otorga la maternidad, estableciendo ésta como su función social única, mientras que al hombre se le atribuye la creación de cultura y el desarrollo de la civilización humana.

Si bien esta división sexual del trabajo era la adecuada para garantizar la supervivencia de la especie humana en los inicios de la humanidad -pues proteger y alimentar a las mujeres significaba garantizar la reproducción del clan o la tribu-, luego ésta se convirtió en una 
imposición cultural, sobre todo con los aportes científicos de las teorías de Darwin, las cuales, supuestamente, demostraban la inferioridad y vulnerabilidad de la mujer en comparación con el hombre. Lerner advierte que:

a causa de su constitución biológica y su función maternal se pensaba que las mujeres no eran aptas para una educación superior y otras actividades profesionales. Se consideraba la menstruación y la menopausia, incluso el embarazo, estados que debilitaban, enfermaban, o eran anormales, que imposibilitaban a las mujeres y las hacían verdaderamente inferiores (1990: 38).

La construcción histórica del patriarcado nos permite reconocer que la normalización y el control de los cuerpos de las mujeres ha sido el requisito necesario para la reproducción de la economía y de un orden social determinado. Bajo el capitalismo, la circulación de la economía basada en la reproducción de la "mano de obra", o la explotación sexual y la pornografía, dan cuenta de que la mantención de los dispositivos de desigualdad de género son los que aseguran la perpetuación del modelo.

En función de lo señalado, afirmamos que la sexualidad se constituye en una forma de organización del poder, mediante instrumentos como el discurso, el cuerpo y la afectividad construida históricamente. Foucault (1999) señala que la sexualidad sirve de instrumento para ordenar las relaciones sociales, construyendo así relaciones de poder.

Por su parte, el patriarcado construye la sexualidad de la mujer bajo sus valores, principios y significaciones, restringiéndola a la reproducción y la maternidad como única expresión, conjugando sexualidad y rol social reducidos a su naturaleza biológica. En este sentido, la sexualidad y el placer sexual quedan bajo el orden patriarcal bajo el dominio del hombre, y la centralidad en el órgano del poder, el falo como fetiche del deseo/placer/ sexualidad. Al carecer la mujer de este órgano, su sexualidad se construye desde la pérdida y la castración, por lo que el placer sexual le es arrebatado, desconectándola de su cuerpo:

La sexualidad en la que nos educan es la sexualidad de un cuerpo despiezado, escindido en 'cuerpo' y alma (...). Lo que llamamos 'cuerpo' es en realidad el subproducto de un cuerpo despiezado y en buena medida desvitalizado. La clave de esta escisión es "la ruptura psicosomática entre la conciencia y el útero" (Cachafeiro y Rodrigáñez 2005: 2).

De esta manera, cualquier otra dimensión de la sexualidad de la mujer que no se corresponda con la reproducción, es criticada y reprochada. El útero es la fuente de la procreación, por ello la posibilidad de experimentar placer es sacralizada y satanizada. Como consecuencia, el deseo sexual en la mujer es sinónimo de perversión, por eso es castrada socialmente, siendo su cuerpo incompleto y desarmado, por lo que debe subordinarse al orden fálico. Las mujeres que han subvertido el orden de género han visto patologizadas sus conductas, desde la histeria femenina hasta los diversos supuestos "trastornos ginecológicos", de los cuales la medicina y la industria farmacéutica han sido los principales cómplices, aliándose con la construcción de una sexualidad desde el Estado.

\section{El aborto en Chile durante el siglo XX}

El aborto irrumpe como problemática de salud pública en el siglo $X X$, a partir de la visibilidad que adquiere en el debate científico-médico desde comienzos de la centuria, la cual se enmarca en 
la preocupación en torno a la profilaxis social en el período. La situación social hacia la década del 30 comenzó a ser preocupante, debido al alza que experimentó el número de abortos, ya que una gran cantidad de mujeres llegaba a los servicios de asistencia con complicaciones producto de una intervención abortiva. Susana Herrera afirma que:

en esos años no se plasmaba en el papel de manera oficial pues nadie podía obviar el alto número de mujeres que día a día llegaban a las maternidades y a las asistencias públicas desgarradas y desangradas por dentro producto de las nefastas intervenciones en sus cuerpos, siendo los médicos (...) testigos de esta realidad pues les tocaba presenciarla (2008: 600).

El aborto adquirió un carácter epidémico al afectar todas las clases sociales, especialmente a las mujeres más pobres. La tasa de mortalidad materna se elevó conllevando la amenaza de una crisis poblacional futura en la sociedad chilena y un sinfín de niños huérfanos, lo que obligó al Estado a reconocer el problema del aborto como un tema de salud pública.

En la década del 30 el aborto se establece como foco de debate, el cual se basa fundamentalmente en las opiniones de quienes apuntaban a un régimen de restricciones y de los partidarios de la legalización. Al respecto, en el Boletín Médico de la Caja de Seguro Obligatorio se reproducía una publicación titulada "La lucha contra los abortos" del Dr. A. Gens' de la Universidad de Moscú, en la cual se señalaba:

De gran actualidad es para Chile este problema, ya que todos los médicos que trabajan en las maternidades, servicios de ginecología y en la

Boletín Médico de la Caja de Seguro Obligatorio, Año I, № 8, p 17. Santiago, enero de 1935.
Asistencia Pública, ven morirse constantemente gran número de mujeres, en la plenitud de la vida, a consecuencia de los abortos criminales. Como hemos dicho, este interesante trabajo lo intercalamos como una información de lo que se hace actualmente en uno de los países del globo con resultados que desde el punto de vista médico, son halagadores. Lo firma uno de los más altos valores científicos que hay actualmente en Europa.

Lo anterior nos permite señalar que, si bien existía desde 1931 en el Código Sanitario, artículo 119, una instrucción respecto al aborto terapéutico, la toma de una conciencia sobre el carácter público y no privado de éste se desarrolló progresivamente. Al mismo tiempo, desdela medicina comenzaron a distinguirsecon claridad los abortos criminales (clandestinos) de aquellos asistidos por especialistas, de manera que, sistemáticamente, fue fortaleciéndose la práctica del aborto.

Dicha realidad también se evidencia en el hecho de que la legislación sobre el aborto terapéutico debió ser modificada en 1968, ya que no se había logrado controlar la epidemia de abortos clandestinos que afectaba a la población chilena. De esto se desprendía, por ejemplo, que los egresos hospitalarios por aborto alcanzaban la cifra de 57.368, de los cuales entre el $75 \%$ y $90 \%$ eran provocados, atribuyéndose a ellos la causa de hasta el $40 \%$ de las muertes maternas (Castro 2009).

De este modo, es posible comprender que el aborto ha sido una práctica histórica que la institucionalidad debió abordar en la medida en que contrariaba el orden. Así, el Estado dio inicio a una progresiva implementación de políticas respecto al aborto, impulsando el uso de métodos anticonceptivos artificiales (píldora, DIU, entre otros), y la planificación familiar mediante la creación de organismos 
estatales destinados a evitar el descalabro demográfico y los efectos sociales vinculados. Éstos son los casos de la Comisión Asesora de Regulación de la Fecundidad y la Asociación Chilena de Protección a la Familia (APROFA), las cuales jugaron un importante rol durante los gobiernos de Eduardo Frei Montalva y Salvador Allende durante la Unidad Popular, gobierno que puso su énfasis en temas de sexualidad y reproducción, salud y bienestar de la familia.

Sin embargo, el aborto, así como el conjunto de los derechos sociales, quedan clausurados desde 1973 a partir de la implantación del proyecto de la dictadura militar, que fija en la "mujer chilena" un actor clave en la búsqueda por otorgar legitimidad al orden conservador. Lo anterior queda de manifiesto en el discurso público desde los primeros años del régimen:

No podría terminar estas palabras referidas al Frente Económico y Social, sin rendir un emocionado homenaje a la mujer chilena que, en forma constante y silenciosa, diariamente colabora a la estabilidad moral y material de nuestros hogares y al progreso social de nuestra Patria².

Y es que en la decisión del mando militar adoptada esa mañana, no estuvo ausente la civilidad, que la esperaba como la única posibilidad para culminar con buen éxito una heroica lucha que, sin eludir ni el riesgo de la propia vida, las mujeres (...), habían enfrentado estoicamente en los tres años de agresión marxista-leninista ${ }^{3}$.

puede citarse la racional adecuación de los descuentos por planilla; las modificaciones introducidas en materia de salas cunas, que protegen verdaderamente a la mujer trabajadora, sin entrabar su acceso al trabajo y la continuidad de

Augusto Pinochet, Cuenta Pública Anual, 11 de septiembre de 1976.

Augusto Pinochet, Cuenta Pública Anual, 11 de septiembre de 1978. la relación laboral en caso de venta o arrendamiento de las empresas ${ }^{4}$.

La imagen de la mujer bajo la dictadura se construye en relación con las claves mujer/madre/ patria, distinguiéndose principalmente dos énfasis en la elaboración del discurso hacia la mujer. Uno en los primeros años de la dictadura, asociado con la figura de la mujer "guardiana del hogar", que apelaba fundamentalmente a la búsqueda de legitimidad cívica del régimen, apuntando a los valores patrios y al resguardo de la seguridad. $Y$ otro en un segundo momento en la década de los 80 , asociado con la expansión del área de servicios, instaurándose la figura de la mujer/ chilena/trabajadora, que destacaba el rol que le cabría en el llamado "progreso material del país".

Al respecto, si bien coincidimos con Mala Htun (2010) respecto de esta doble condición impuesta a las mujeres bajo las dictaduras militares en América Latina, es necesario precisar que la incorporación de la mujer al mercado laboral en condiciones de desigualdad y trabajo flexible y precario, lejos de corresponderse con un cambio de los roles de género, responde a las condiciones de desigualdad impuestas bajo el neoliberalismo, por ello no una transgresión, sino una mutación de los roles tradicionales de género. Esta autora señala que:

[e]l militarismo latinoamericano produjo efectos contradictorios en las relaciones de género y en la situación de la mujer. A pesar de su discurso conservador, las políticas económicas militares impulsaron a un número sin precedentes de mujeres hacia la fuerza laboral, rompiendo con las distinciones público-privado y estableciendo dinámicas sociales que desafiaron los papeles de género tradicionales (2010: 43).

Augusto Pinochet, Cuenta Pública Anual, 11 de septiembre 1981. 
La dictadura necesitaba, además, incrementar la tasa de natalidad en el país, para sustentar las demandas del modelo económico neoliberal recién implementado. Es por ello que, aprovechando los argumentos de la Iglesia Católica para defender la vida, suprime la educación sexual y la implementación de los métodos anticonceptivos como política estatal (Herrera 2008).

Junto con ello, al establecerse la ley $\mathrm{N}^{\circ}$ 18.826 en reemplazo de la normativa sobre aborto terapéutico presente en el Código Sanitario desde los años 30, se dispone sólo la interrupción del embarazo por situaciones externas e involuntarias, siendo restringida en extremo su causal, lo cual derivó, en la práctica, en su criminalización. Es de esta manera que las políticas de control poblacional dejaron de responder a las necesidades sanitarias y a los derechos sexuales y reproductivos de los individuos, para responder, en su lugar, a las necesidades del nuevo sistema económico.

Así como la estructura económica y el orden social de la dictadura se prolongan y profundizan en la posdictadura, la dura represión y la lógica de la política de consensos implementada por los partidos de la naciente Concertación, fueron postergando las reivindicaciones de los movimientos sociales, y abandonando las banderas de la democratización en materia de justicia social. Asimismo, el rol de tutela de los poderes conservadores del país permanece vigente en la sociedad chilena, otorgando continuidad a los roles de género tradicionales y a la división sexual del trabajo en la posdictadura.

Lo anterior se expresa en los tardíos debates en materia de género, siendo ejemplo de ello que, recién en 1994, el Estado reconoce la existencia del maltrato intrafamiliar como una expresión particular y específica de la violencia. Seguidamente, el año 2004 se aprueba la ley de divorcio, siendo Chile uno de los últimos países del mundo en legislar al respecto. Por su parte, el "femicidio" se reconoce legalmente en nuestro país, como expresión de la profundización de la violencia de género, recién hacia finales del año 2010. Por último, el aborto tuvo que esperar hasta el año 2015 para incorporarse como parte de un programa de gobierno, bajo la modalidad de despenalizar el aborto terapéutico bajo tres causales.

\section{La situación del aborto durante la posdictadura: El debate político}

En los primeros años de la transición pactada a la democracia en los 90, el principal debate al interior de la clase política se vinculaba con las relaciones cívico-militares, teniendo como foco de conflicto las violaciones a los derechos humanos ocurridas durante la dictadura. Es por ello que, al existir una deuda pendiente en esta materia, ampliar la discusión en torno a otros derechos sociales, económicos y sexuales, fuera un proceso que se postergó y que emergió enérgicamente desde las reivindicaciones de los movimientos sociales.

Es así como la discusión del aborto se desarrollaría avanzada la posdictadura. Principalmente, ésta tomaría lugar en el debate público como una problemática instalada por las organizaciones feministas, las cuales presionan paulatinamente a la clase política para incorporar la temática en los programas de sus campañas.

La estrategia central en el tratamiento mediático de la temática ha sido desplazarla desde el 
seno de la ciudadanía al plano de "lo moral", en manos de los llamados "especialistas", cuando en realidad es una cuestión política de competencia de la sociedad y, en particular, de las mujeres. De esta manera, los argumentos continuamente esbozados para oponerse a la despenalización del aborto y condenar a quienes lo practican son la defensa de la vida del embrión, y la exaltación de la maternidad como un rol al que las mujeres no pueden negarse, porque se afirma que ser madres es su función en la sociedad, determinada por su naturaleza biológica.

Sin embargo, respecto a nuestra legislación penal sobre el aborto, hay un punto importante que analizar. Por una parte, en el Código Penal chileno, el aborto aparece tipificado como delito en el apartado de Crímenes y Delitos contra el Orden Familiar y la Moralidad Pública, pero no aparece en Crímenes contra la Vida y la Integridad Física de las Personas, como debería ser si los argumentos que lo condenan como práctica aluden al derecho a la vida de los seres vivos. Por otra parte, el artículo 344 dice que:

La mujer que causare su aborto o consintiere que otra persona se lo cause, será castigada a presidio menor en su grado máximo [de 3 años y un día a 5 años]. Si lo hiciere por ocultar su deshonra, incurrirá en la pena de presidio menor en su grado medio [de 541 días a 3 años y un día $]^{5}$.

De esta forma, la atenuante referida al honor de una mujer -y al honor de la familia a la que ésta pertenece- nos lleva a cuestionar si en la legislación chilena se está protegiendo la vida o sólo la moral sexual, restringiendo los derechos sexuales y reproductivos de las mujeres. ¿Importa menos el embrión cuando el aborto se

Código Penal de la República de Chile, artículo 34. realiza para ocultar la deshonra de una mujer? La existencia de dicha atenuante no es más que la expresión legal del doble discurso moral que existe en la sociedad chilena, cargada aún de principios y valores profundamente conservadores.

Por una parte, se condena a una mujer que se realiza un aborto a una pena menor si la intervención se realizó para "eliminar su deshonra", y a una pena mayor si ésta se llevó a cabo por motivos socioeconómicos, por si el embarazo era el resultado de una violación, por si se realizó por motivos terapéuticos, entre otras causales. Por otra parte, la existencia de este doble discurso permite que las personas que poseen mayores recursos económicos acudan a centros de salud privados donde se realizan abortos de manera segura, bajo todas las condiciones de salubridad y seguridad adecuadas, con la complicidad del médico tratante y sin obtener consecuencias legales por infringir la ley.

En el comienzo de la posdictadura en Chile, algunos sectores políticos se mostraron abiertos a debatir sobre una ley de aborto terapéutico, mientras que otros querían mantener el legado de Pinochet. Para abordar las características del debate sobre el aborto, expondremos los discursos que se registran en la prensa al respecto, con el objetivo de evidenciar que la temática del aborto ha sido instrumentalizada por la clase política, como principal mecanismo para generar distinciones al interior de las coaliciones, pero no siendo parte de un proyecto político democrático que avance en la legalidad.

En 1993, bajo el gobierno de Patricio Aylwin, emergen débilmente en la esfera pública las 
temáticas del divorcio y el aborto. Así, La Nación publica en noviembre de ese año lo siguiente:

A la vez, los jóvenes comunistas criticaron a las diputadas María Angélica Cristi y Evelyn Matthei por su oposición a una ley de divorcio y a legislar sobre el aborto, señalando que promueven la protección de "la familia en el sentido más primitivo de su concepción: la anulación de la mujer a cambio de la mantención del statu quo y la doble moral”.6.

Serían los representantes de la derecha civil los encargados de velar por el mantenimiento del proyecto de la dictadura en los primeros años de la llamada transición, negándose a la posibilidad de dialogar al respecto. Sin embargo, serían representantes de este sector los que posteriormente utilizarían la temática del aborto como recurso político para ampliar su electorado.

Entre 2006 y 2010, Michelle Bachelet asume el cargo de Presidente de la República. Se establece bajo su gobierno, como parte de la política de salud pública, la distribución gratuita de la "píldora del día después". Dicha iniciativa recibió duras críticas, y en la práctica se mantuvo como "letra muerta", en la medida en que la decisión de su distribución quedó en manos de los alcaldes. Eduardo Díaz (PRI), en ese momento, expresó:

"Como cristianos acogemos plenamente el llamado de los pastores de las iglesias evangélicas y católicas a defender el derecho a la vida y a la familia chilena, amenazado por las insistencias (...) de seguir intentando la distribución de una píldora donde hay dudas razonables de que puede ser abortiva", expresó Díaz ${ }^{7}$.
De los fragmentos anteriores es posible desprender dos puntos claves. Primero, Eduardo Díaz -como muchos otros- recurre a un argumento religioso para defender su negativa a la distribución de la píldora del día después, lo que no se corresponde con la laicidad constitucional del Estado chileno. Y segundo, profundiza su postura de manera valórica al sugerir que la píldora podría ser abortiva, cuando se ha comprobado científicamente que no lo es. Como consecuencia, es imposible abrir el debate político para legislar sobre el aborto, cuando con respecto al uso de la píldora del día después persisten opiniones profundamente disidentes dentro de la misma clase política, dividiéndola.

Reconocemos dos fases en la elaboración de un discurso de derecha en materia de aborto: un primer momento, caracterizado por la vigencia de la figura de Augusto Pinochet en la esfera pública nacional, que abarca buena parte de la década de los 90, donde los llamados temas "valóricos" son desplazados en beneficio de la unidad del bloque opositor. Un segundo momento se expresa con claridad el año 2010, con la apertura de un sector de la derecha a debatir sobre esta temática, siendo la propia Evelyn Matthei (UDI), entonces senadora, quien, junto con el senador Fulvio Rossi (PS), presentaron un proyecto de ley para reestablecer el aborto terapéutico. Este giro de la derecha se explica como un mecanismo para "renovarse" y ampliar su base social de apoyo.

Es desde el año 2012, a propósito de la discusión llevada a cabo en el senado para despenalizar el aborto terapéutico, que se desarrolla un intenso debate centrado mediáticamente en el bajo nivel argumentativo de los discursos. Al respecto, emblemático es el discurso ultra-conservador de la Unión 
Demócrata Independiente (UDI), encarnado en la senadora Ena Von Baer, donde señalaba que la mujer:

no tiene derecho, desde mi punto de vista, una mujer que presta el cuerpo en el fondo, presta el hogar a esa vida que se va a desarrollar, a terminar con esa vida (...) la vida que se gesta dentro de una mujer para mí es una vida completamente distinta ${ }^{8}$.

En dicho debate, a favor de despenalizar el aborto terapéutico, se encuentran partidos de la Concertación como el Partido Socialista, el Partido Radical y el Partido por la Democracia, mientras que en contra de su despenalización se encuentra la Unión Demócrata Independiente -con las posturas más extremas-, la Democracia Cristiana y Renovación Nacional. Al interior de esta última coalición existió un sector que se abrió a debatir la problemática, lo que a la larga desencadenó, por ésta y otras temáticas, un quiebre interno.

Este debate sería recogido en parte en el programa del segundo gobierno de Michelle Bachelet, quien el 21 de mayo de 2014, durante la cuenta pública, anuncia la presentación del proyecto de ley que despenaliza el aborto terapéutico en casos de violación, peligro de la vida de la madre e inviabilidad del feto. La presentación de este proyecto se realizó el 31 de enero del 2015. Al respecto destacamos el rol que asigna al Estado en esta materia:

Debemos reconocer que el Estado, en estas situaciones extremas no puede imponer una decisión a las mujeres, ni penalizarlas, sino entregar alternativas, respetando su voluntad, ya sea que deseen continuar con el embarazo u optar por interrumpirlo, para asegurar el completo respeto de sus derechos ${ }^{9}$.

Radio Cooperativa, 14 de marzo del 2012.

Mensaje $N^{\circ} 1230-362$.
Podemos señalar que si bien se valora la presentación de este proyecto, y es, sin duda, un avance en la materia, éste encierra varios elementos que entran en contradicción con la profundización democrática. Por ejemplo, se siguen estableciendo como referencias argumentos en función de los derechos que otorga la Constitución del 80 , reconocido instrumento ilegítimo por su origen en dictadura. Además, junto con el enfoque restringido de la despenalización del aborto terapéutico, se suman las limitantes de las causales establecidas, lo que, a la larga, significa que el Estado impone una decisión a las mujeres.

Dicho esto, es posible resumir que, durante los primeros veinte años de transición política, ha sido muy difícil abrir espacios de discusión para despenalizar el aborto voluntario, incluso recuperar el derecho en su modalidad terapéutica, ya que la clase política no ha estado a la altura de este debate, ni tampoco ha existido una demanda transversal en los movimientos sociales. Hemos querido sistematizar en este artículo algunos elementos que permitan profundizar el debate en torno al aborto porque, sin duda, las propuestas de aborto legal, seguro y sin restricciones vendrán de la voz de las organizaciones feministas y de los movimientos ciudadanos que las impulsen.

\section{Conclusiones}

A lo largo de la posdictadura varias iniciativas para legislar sobre el aborto han "dormido" en el Congreso, principalmente por la búsqueda del "bien mayor" en relación con los equilibrios al interior de la coalición gobernante, actualmente Nueva Mayoría. La discusión sobre el aborto ha estado cruzada por la vigencia de los 
sectores conservadores que han intentado prolongar el proyecto societal de la dictadura, que se encarna en la constitución del 80 y en el conjunto de su estructura institucional. Por ello, el mantenimiento de la penalización del aborto en el país desnuda el entramado de la posdictadura y la falta de derechos democráticos.

Los discursos construidos en el debate público de la clase política han estado marcados por argumentos que cristalizan una visión moralizante, científico-médica y jurídica, los cuales han buscado instalar la problemática desde el "monopolio" de los especialistas. Esta estrategia se ha empleado para evitar que la discusión se instale en la sociedad en su conjunto, como reivindicación del movimiento feminista, y que, a su vez, resulta transversal en los movimientos sociales.

Las actuales propuestas en torno a la despenalización del aborto terapéutico por tres causales siguen siendo insuficientes en relación con los derechos de las mujeres de elegir y decidir sobre sus cuerpos y sus proyectos de vida. Avanzar hacia el aborto libre, legal y gratuito es un paso hacia la profundización democrática. Es un imperativo ético y político por la igualdad social en el país.

En este contexto, la realidad estadística se distancia de la jurídica. Mientras cerca de 160.000 mujeres se inducen abortos al año ${ }^{10}$, parte de la clase política sigue resistiéndose a legislar al respecto, y, si bien el debate se encuentra instalado con claridad y es parte de un programa de gobierno, no existen certezas de la aprobación del aborto terapéutico, ni menos sobre la voluntad política de avanzar en el aborto libre y gratuito. Sin la existencia de organizaciones feministas vigilantes, las propuestas de leyes permanecerían "durmiendo" en el Congreso.

Por ello, en la medida en que la temática se instale como un derecho en el seno de la sociedad civil, será posible avanzar no sólo en torno al aborto, sino en una política de derechos sexuales y reproductivos que tenga expresión en el ámbito de la salud, educación y equidad de género. Esto ocurrirá cuando la decisión de los proyectos de vida individual y colectiva esté, efectivamente, en manos de las mujeres. 


\section{Bibliografía}

Cachafeiro, A. y Rodrigáñez, C. 2005. "La sexualidad de la mujer". Revista Ekintza Zuzena 25: 1-10.

Castro, R. 2009. "Iniciativa FIGO de prevención del aborto inseguro: Visión del Ministerio de Salud". Revista Chilena de Obstetricia y Ginecología 74 (2): 1-3.

De Lauretis, T. 1989. Technologies of gender. Essays on theory, film and fiction. London: Macmillan Press.

Foucault, M. 1999. Historia de la sexualidad. Tomo I. La voluntad de saber. México D.F.: Siglo XXI.

Herrera, S. 2008. "Aborto inducido: ¿Un secreto de mujeres o una problemática de género?". Mujeres chilenas. Fragmentos de una historia. Montecino, S. (Comp.). Santiago: Editorial Catalonia. 599-609.

Htun, M. 2010. Sexo y Estado. Aborto, divorcio y familia bajo dictaduras y democracias en América Latina. Santiago: Ediciones Universidad Diego Portales. Hunneus, C. 2014. La democracia semisoberana. Santiago: Taurus.

Kirkwood, J. 1983. La política del feminismo en Chile.

Santiago: FLACSO.

Lerner, G. 1990. La creación del patriarcado. Barcelona:

Editorial Crítica.

Mackinnon, C. 1995. Hacia una teoría feminista del Estado. Madrid: Editorial Cátedra. Scott, J. 2008. Género e historia. México D.F.: Fondo de Cultura Económica.

Varela, N. 2005. Feminismo para principiantes. Barcelona: Ediciones B. 
